\title{
Capítulo 10
}

\section{Projetos temáticos como alternativa para o ensino de compostagem: um relato de experiência}

Tatiane Cristina Dal Bosco

Flávia Gonçalves

Cristiane Beatriz Dal Bosco

Rezzadori

Resumo: O desenvolvimento de projetos temáticos permite aos alunos analisar os problemas e acontecimentos dentro de um contexto e em sua globalidade, utilizando para isso, os conhecimentos presentes nas disciplinas e sua bagagem sociocultural. Por meio dele, o aprendizado deixa de ser uma mera reprodução do conhecimento, pois o aluno torna-se corresponsável pela sua aprendizagem e o professor torna-se um orientador, a ponte entre o que se sabe e o conhecimento novo. Baseado nestes aspectos, neste capítulo será relatada a experiência do desenvolvimento de um projeto temático na disciplina Gerenciamento e Tratamento de Resíduos Sólidos, do Curso de Engenharia Ambiental da UTFPR - Londrina, experiência que vem sendo realizada desde 2010. A partir da temática "compostagem" os alunos foram levados a analisar o problema levantado, planejar ações, resolver problemas, tomar decisões, desenvolver estratégias e a envolver-se na tarefa de aprendizagem a partir da vivência das mais variadas atividades (pesquisas, trabalhos em grupo e de campo, entre outros). Pode-se afirmar que o trabalho realizado nesta disciplina teve boa aceitação por parte dos alunos, sendo uma proposta alternativa viável para o ensino de engenharia, pois considera a formação global do aluno e torna o processo de ensino e aprendizagem mais significativo, cooperativo e interessante.

Palavras-Chave: Ensino de Engenharia. Gerenciamento e Tratamento de Resíduos Sólidos. Vermicompostagem. 


\section{Introdução ao estudo}

Não é incomum, ao avaliar as propostas de ensino e aprendizagem presentes nas escolas e universidades brasileiras, deparar-se com práticas pedagógicas influenciadas por uma visão tipicamente conservadora, que leva à reprodução do conhecimento com a ênfase apenas na repetição, na memorização e na cópia. Para estes casos, a avaliação ministrada nada mais é do que um indicativo de acúmulo de informações registradas e não necessariamente das capacidades apreendidas pelo aluno (BERBEL et al., 2000). Essa concepção revela que "os alunos se colocam como sujeitos passivos, sempre à mercê das ordens dos professores, lidando com um conteúdo completamente alienado de sua realidade e em situações artificiais de ensino e aprendizagem" (LEITE, 1996).

Essa forma tradicional de ensinar contribui muito pouco para o desenvolvimento do aluno e por isso é preciso ressignificar o espaço educativo, promover a reflexão, a pesquisa e a investigação sobre pressupostos teóricos abordados (SANTOS e BUENO, 2002). A proposta de uma prática pedagógica baseada nestes objetivos atinge seu verdadeiro sentido no que concerne à preparação profissional no ensino superior, o que por fundamento requerer do sujeito uma ampla compreensão da realidade, de modo que, frente a uma adversidade, o mesmo consiga contornar situações desafiadoras por meio do raciocínio e da tomada de decisão, o que lhe exigirá flexibilidade, capacidade de análises, articulações pessoais, entre outros requisitos (BERBEL et al., 2000).

Portanto, segundo Behrens (2000), faz-se necessário promover atividades que permitam a participação ativa do aluno no processo de produção e compreensão do conhecimento, garantindo a ele uma aprendizagem significativa com autonomia. Uma das alternativas que vem de encontro com esta abordagem, sobretudo com a busca por uma visão holística, é o desenvolvimento de projetos de trabalho ou projetos temáticos, que surgiram no início do século passado com os membros da Pedagogia Ativa1. Conforme defende Hernández (1998),

1 "A Pedagogia Ativa tem como fundamento os estudos do suíço Adolphe Ferrière, que no início do século XX foi um dos primeiros a usar o termo "ativo" em publicações escolares. É uma das bases da "Educação Nova”, tendência pedagógica iniciada na França. Pedagogos como Freinet, Montessori, Steiner ou Decroly também defendem uma metodologia diferente da "tradicional” pedagogia de transmissão. A Pedagogia Ativa é mais flexível que o ensino 'tradicional', para o qual há uma referência (programa a seguir) e avaliações para testar o conhecimento. Com métodos ativos, o aluno é enquadrado no processo de aprendizagem, porém se mantém independente e autônomo em sua abordagem. O trabalho é feito em grupos e o aluno é envolvido em situações (reais ou imaginárias) para que possa utilizar suas habilidades e desenvolvê-las durante o treinamento" (MAHÉ, 2016). 
Os projetos assim entendidos apontam outra maneira de representar o conhecimento escolar baseado na aprendizagem da interpretação da realidade, orientada para o estabelecimento de relações entre a vida dos alunos e professores e o conhecimento que as disciplinas [...] e outros saberes não disciplinares vão elaborando. Tudo isso para favorecer o desenvolvimento de estratégias de indagação, interpretação e apresentação do processo seguido ao estudar um tema ou um problema que, por sua complexidade, favorece o melhor conhecimento dos alunos e dos docentes de si mesmos e do mundo em que vivem (HERNÁNDEZ, 1998).

Esse enfoque possibilita a análise de problemas e acontecimentos dentro de um contexto e em sua globalidade, utilizando para isso, os conhecimentos presentes nas disciplinas e a bagagem sociocultural do aluno e do professor. A aprendizagem deixa de ser uma mera reprodução do conhecimento para se tornar uma tentativa de resolver uma situação problemática. Ela passa a ser colaborativa, exigindo o envolvimento de todos: o professor deixa de ser o transmissor dos conteúdos para ser um guia, um orientador de caminhos, a ponte entre o que se sabe e o conhecimento novo, ao mesmo tempo em que desperta novas inquietações e questões de investigação; o aluno, por sua vez, que era o receptor das informações, torna-se agora o sujeito do processo, corresponsável e comprometido com a sua aprendizagem, uma vez que necessita buscar soluções aos problemas por ele elaborados.

Ao se promover o desenvolvimento de um projeto temático, o tema pode surgir de um aluno, de um grupo de alunos, da turma, do professor ou da própria conjuntura. Independentemente de quem o propõe, deve-se considerar o tratamento dado ao tema escolhido e o envolvimento de todo o grupo no processo, ou seja, o importante é criar condições para que o "problema passe a ser de todos, com um envolvimento efetivo na definição dos objetivos e das etapas para alcançá-los, na participação das atividades vivenciadas e no processo de avaliação“ (LEITE, 1996).

Para tanto, três momentos devem ser configurados, conforme pode ser observado na Figura 10.1. Apesar da necessidade da existência desses momentos no desenvolvimento de um projeto, é fundamental destacar que eles não são etapas estanques, mas sim

processos contínuos que não podem ser reduzidos a uma lista de objetivos e etapas. Refletem uma concepção de conhecimento como produção coletiva, onde a experiência vivida e a produção cultural sistematizada se entrelaçam, dando significado às aprendizagens construídas. Por sua vez, estas são utilizadas em outras situações, mostrando, assim, que os 
educandos são capazes de estabelecer relações e utilizar o conhecimento apreendido, quando necessário (LEITE, 1996).

\section{PROBLEMATIZAÇÃO}

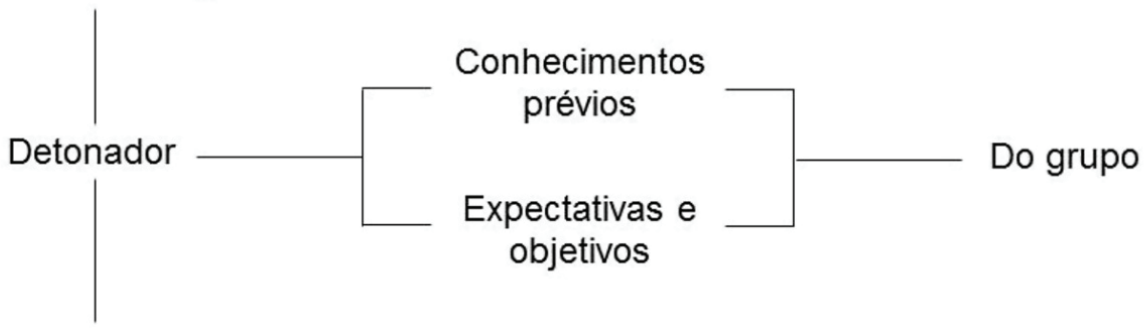

\section{Organização do}

projeto

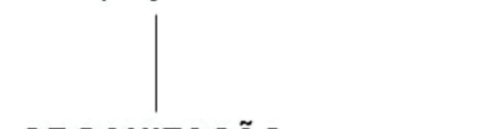

\section{ORGANIZAÇÃO}

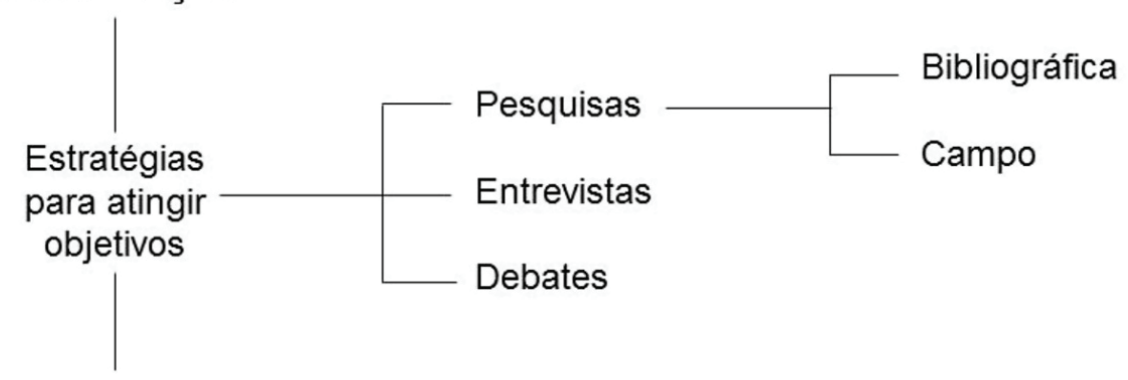

\section{Realização}

do projeto

SÍNTESE

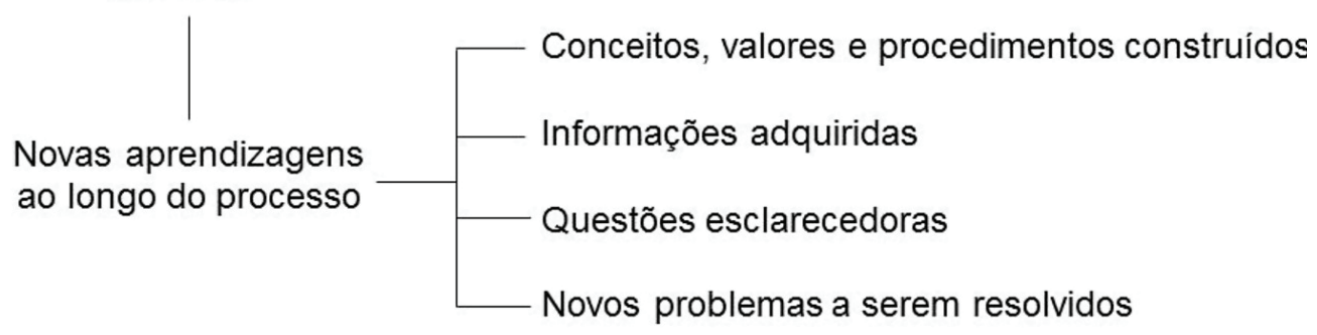

Figura 10.1 Esquema ilustrativo do desenvolvimento de um projeto.

Fonte: LEITE, 1996 
Uma vez definido o tema, que pode nascer "do currículo oficial, proceder de uma experiência comum [...], originar-se de um fato da atualidade, surgir de um problema proposto pela professora ou emergir de uma questão que ficou pendente em outro projeto" (HERNÁNDEZ; VENTURA, 1998), acontece a problematização do mesmo. Nesta etapa, os alunos expressam seus conhecimentos e levantam hipóteses sobre o problema em questão. É aqui que o professor percebe o que os alunos já sabem e o que ainda não sabem sobre o tema. É também a partir das questões levantadas nesta etapa que o projeto é organizado pelo grupo (LEITE, 1996).

Posteriormente, acontece o desenvolvimento do projeto. Aqui criam-se as estratégias e propostas de trabalho para buscar respostas às questões e hipóteses levantadas. Os alunos pesquisam sobre o tema, trazem para o grande grupo as informações obtidas, discutem para, então, produzir o conhecimento coletivamente. Nesse processo, a ação do aluno é fundamental, pois eles

descobrem que também têm uma responsabilidade na sua própria aprendizagem, que não podem esperar passivamente que o professor tenha todas as respostas e lhes ofereça todas as soluções, especialmente porque, como já foi dito, o educador é um facilitador e, com frequencia, um estudante a mais (HERNÁNDEZ; VENTURA, 1998).

Por fim, realiza-se a síntese do projeto em que são apresentados os resultados da aprendizagem e a avaliação do processo. $\mathrm{Na}$ apresentação dos resultados, alunos e professor ordenam as atividades que realizaram durante todo o desenvolvimento do projeto e compartilham o conhecimento obtido entre eles e com a comunidade. A avaliação, por sua vez, é mediada pelo professor que dialoga e discute com os alunos o envolvimento, desenvolvimento e qualidade do que foi proposto.

Entendida nessa perspectiva, a opção pelo desenvolvimento de projetos temáticos possibilita uma aprendizagem pluralista e o acesso a maneiras diferenciadas de aprender (BEHRENS; JOSÉ, 2001). De modo geral, a inclusão de projetos no contexto da aprendizagem leva o aluno inicialmente a um contato mais direto com a pesquisa, gerando posteriormente discussões coletivas críticas e reflexivas que lhes proporciona a convivência com a diversidade de opiniões, fazendo das atividades metodológicas situações de aprendizagem significativas para todos que dela participam.

Deste modo, a fim de apresentar um relato pautado neste tipo de proposta pedagógica, este capítulo apresenta a análise do projeto temático intitulado "Projeto de Compostagem“ realizado no primeiro semestre de 2015, com 24 alunos 
matriculados na disciplina Gerenciamento e Tratamento de Resíduos Sólidos, do Curso de Engenharia Ambiental da Universidade Tecnológica Federal do Paraná - câmpus Londrina. O projeto teve por objetivo proporcionar aos alunos a vivência de uma situação concreta para o tratamento de resíduos sólidos por meio da técnica da compostagem.

\section{0 desenvolvimento do projeto de compostagem}

A professora responsável pela disciplina escolheu o tema Compostagem por se tratar de uma técnica de ampla aplicação no tratamento de resíduos sólidos e porque a Política Nacional de Resíduos Sólidos, promulgada pela Lei n. 12305/2010 (BRASIL, 2010) sugere a adoção desta técnica para os municípios tratarem a fração orgânica de seus resíduos, aumentando a vida útil de aterros sanitários, que devem ser destinados a receber apenas rejeitos. Deste modo, trata-se de um tema de suma importância para o engenheiro ambiental que vivenciará na prática da profissão situações que demandarão dele habilidades para a condução de processos de tratamento por meio desta técnica.

Conforme pode ser observado na Figura 10.2, a primeira etapa do projeto foi a problematização, em que os alunos foram estimulados a pensar em resíduos do meio urbano ou rural passíveis de serem tratados por meio da compostagem e que representassem um passivo ambiental se não bem gerenciados, como por exemplo, dejetos animais, restos de comida provenientes de restaurantes, podas de árvores, resíduos agroindustriais, entre outros. Tal decisão esteve pautada nas experiências pessoais, nas visitas técnicas realizadas ao longo do curso, no local onde residem ou estagiam, em palestras em que participam e conhecem a realidade dos passivos ambientais relacionados a resíduos no âmbito local/regional.

Uma vez realizado esse momento inicial, a professora apresentou a abordagem teórica do tema "compostagem", que contemplou a definição, importância para o gerenciamento de resíduos sólidos, vantagens da realização do processo, explicação quanto aos resíduos que podem ser compostados, parâmetros que precisam ser monitorados ao longo do processo, métodos para sua realização e, por fim, o dimensionamento de pátios de compostagem. 


\section{Problematização}

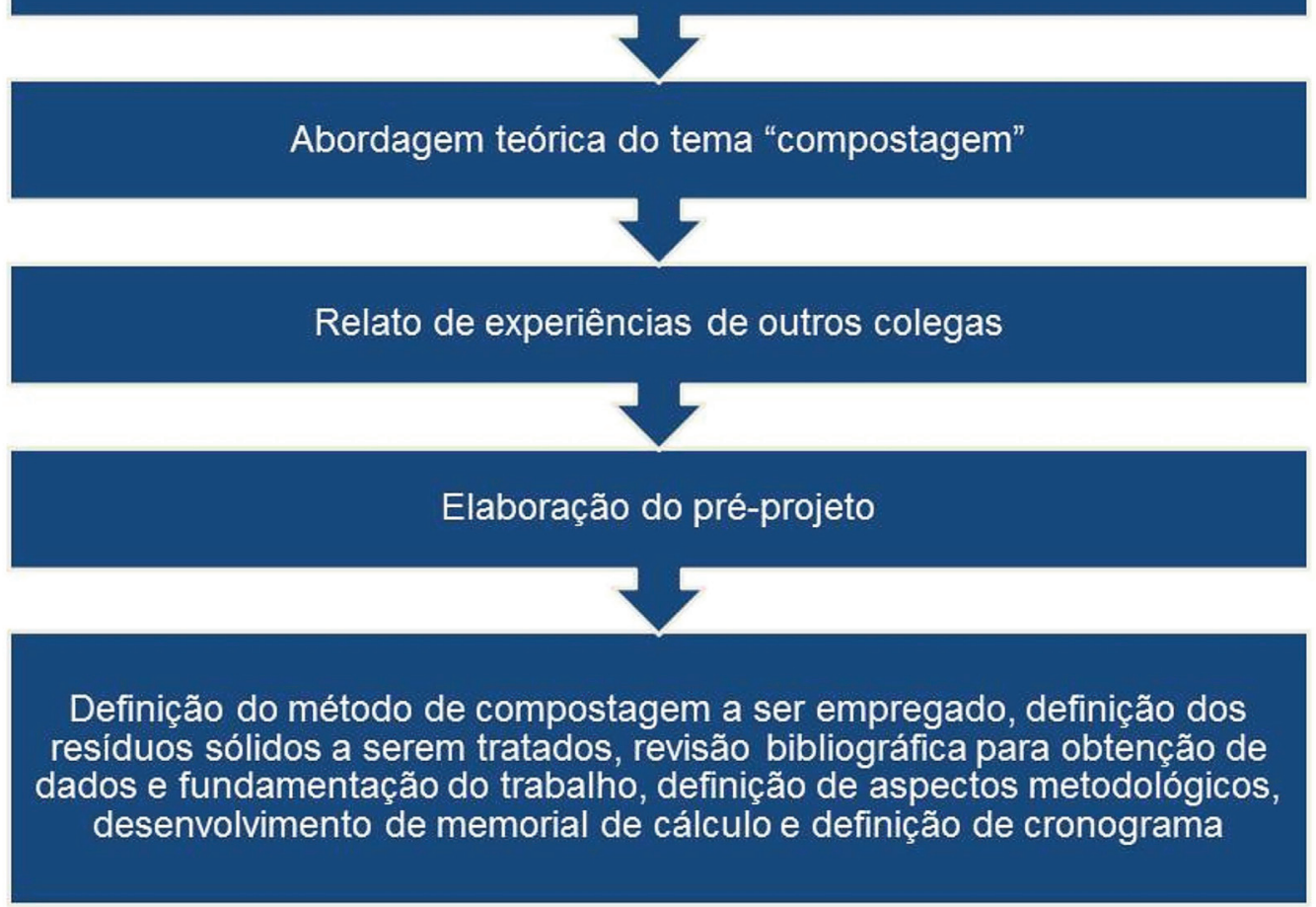

Figura 10.2 Momentos do desenvolvimento do projeto.

Em busca de maiores informações sobre a temática, alunos que já haviam realizado a disciplina e desenvolvido projetos de compostagem foram convidados a apresentar suas experiências e ressaltar dicas práticas para a condução do processo. A partir deste embasamento teórico-prático, os alunos se organizaram em grupos de quatro pessoas e foram direcionados para a elaboração de um pré-projeto, que continha: Introdução, Objetivos, Metodologia, Resultados esperados, Cronograma e Referências bibliográficas. Neste pré-projeto foram especificados os resíduos a serem utilizados, o método, os cálculos de quantidades de resíduos e o dimensionamento do pátio de compostagem. Para tanto, necessitaram fazer pesquisas na região para verificar onde conseguir os resíduos para a compostagem e pensar na justificativa do projeto, visando resolver uma problemática real do gerenciamento de resíduos sólidos.

Este pré-projeto foi corrigido pela professora, que deu feedback aos grupos, de modo a realizarem possíveis correções e a pensarem em detalhes práticos da metodologia. Em seguida, definiu-se um dia para a execução do projeto, ou seja, para a montagem das leiras de compostagem. A partir de então, diariamente 
os alunos precisavam coletar, manualmente, dados de temperatura, monitorar a umidade e, ao menos duas vezes por semana, promover a aeração por meio de revolvimentos manuais. Quatro aulas de laboratório, para monitoramento de parâmetros físico-químicos foram realizadas ao longo do processo. $\mathrm{O}$ monitoramento teve duração aproximada de 60 dias.

No momento da síntese das atividades, os alunos foram orientados a elaborarem um relatório técnico, contendo: Introdução, Objetivos, Metodologia, Resultados e Discussão, Conclusões, Referências bibliográficas e Avaliação pessoal dos integrantes do grupo acerca do processo de aprendizagem proporcionado pelo projeto. Depois de entregue o relatório, os alunos fizeram a sua apresentação em sala de aula, utilizando-se de slides e projeções, para socializar a experiência, avaliar e receber o feedback acerca dos resultados e do processo.

Por fim, um questionário, composto pelas questões abaixo, foi respondido pelos alunos envolvidos com o intuito de obter uma avaliação do processo vivenciado.

- De 0 a 10, que nota você atribui ao projeto de compostagem utilizado no processo de ensino e aprendizagem?

- A aprendizagem do tema compostagem por meio de projeto foi válida?

- Qual é a importância do projeto de compostagem para a sua formação?

As respostas obtidas foram catalogadas e serão apresentadas e discutidas a seguir, juntamente com a análise do projeto realizado.

\section{Análise dos resultados}

Conforme discutido anteriormente, a escolha do tema a ser desenvolvido em um projeto pode ser apontado tanto pelo professor quanto pelo aluno. $\mathrm{O}$ importante é que o tema escolhido propicie crescimento e o envolvimento de todos. A temática "Compostagem" foi de grande relevância uma vez que é um assunto de vasta aplicação no tratamento de resíduos sólidos, relativamente fácil de ser realizada e de baixo custo, o que possibilita o uso dessa técnica pelo engenheiro ambiental para a solução de passivos ambientais em diferentes situações. A sua escolha garantiu uma nova organização dos conteúdos estudados tendo em vista que alunos e professora estiveram envolvidos em discussões e atividades voltadas para o conhecimento da temática em questão.

Definido o tema, deve-se considerar o que os alunos já sabem sobre o mesmo. É a partir daí que o projeto pode ser organizado e desenvolvido. A partir dos relatos apresentados pelos alunos, pôde-se perceber que a maior parte conhecia pouco sobre o tema e quando o conhecia, estas informações careciam de maior detalhamento e fundamentação. Por este motivo, foi de fundamental importância a abordagem teórica do assunto e o relato de experiências apresentado pelos colegas que já haviam cursado a disciplina e vivenciado um momento semelhante. 
No desenvolvimento do projeto, notou-se que os alunos se sentiam incialmente confusos e dependentes da professora no momento de definição dos resíduos e dos métodos de compostagem. Havia insegurança na tomada de decisão e na busca de soluções para problemas que eles mesmos levantaram. Além disso, não acreditavam que poderiam ser corresponsáveis pela aprendizagem e que conseguiriam produzir o seu próprio conhecimento. No entanto, conforme o cronograma foi sendo cumprido, passaram a compreender seu papel no processo de ensino e aprendizagem e, mediados pela professora, tornaram-se agentes do processo e cumpridores dos compromissos firmados com o grupo para a construção individual e coletiva do conhecimento.

Os conteúdos trabalhados nas disciplinas do curso deixaram de ser cumulativos para se tornar uma alternativa para resolver a situação-problema proposta, sanar os conflitos gerados, aprofundar as necessidades e auxiliar na formação global do aluno. Pode-se citar como exemplo os conhecimentos advindos de áreas como a Química, Matemática, Biologia e Gestão.

Com relação à síntese do projeto, notou-se que os alunos foram capazes de confrontar a teoria e a prática, apresentaram explicações para os resultados obtidos e se deram conta da importância do trabalho coletivo para o sucesso do projeto proposto. Além disso, fizeram sugestões para futuras experiências e sentiram-se motivados a compartilhá-las com os demais colegas e professores, bem como a conduzir processos de compostagem na sua atuação profissional futura.

Por fim, quando convidados a atribuir uma nota para o projeto de compostagem vivenciado, observa-se que $95 \%$ dos alunos atribuíram nota acima de 8 (Figura 10.3).

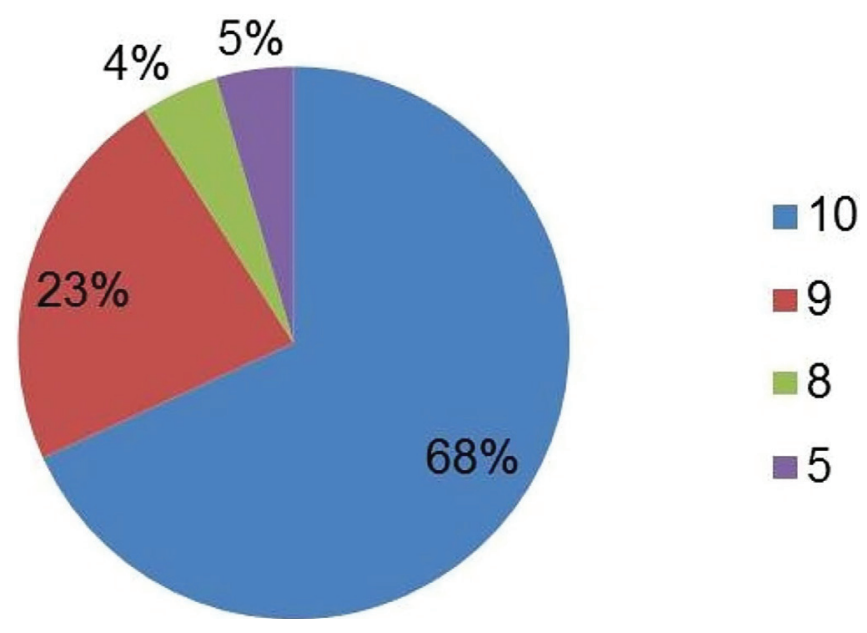

Figura 10.3 Notas atribuidas pelos alunos (de 0 a 10 ) para o projeto de compostagem utilizado no processo de ensino-aprendizagem. 
Pode-se inferir a partir das notas atribuídas e dos relatos apresentados pelos alunos acerca do trabalho realizado, que o desenvolvimento do referido projeto temático teve uma boa aceitação por parte dos alunos envolvidos. Segundo os relatos abaixo apresentados, apesar de ser uma proposta diferenciada, que demanda tempo e envolvimento, cansativa por requerer o monitoramento do processo diariamente por cerca de dois meses, ela despertou o interesse e tornou o ensino e a aprendizagem dos conceitos mais significativos uma vez que o aluno conseguiu vivenciar na prática o que poderia ser trabalhado apenas na teoria.

1. "Muito importante do ponto de vista prático. Vimos na prática a teoria. E isso é necessário".

2. "Dá trabalho. Porém, é muito válido adquirir prática em algo que podemos trabalhar. No final, valeu a pena. Foi gratificante".

3. "Muito bom! Foi um dos trabalhos mais interessantes que fiz durante o curso até agora”.

No que diz respeito à importância do trabalho com projeto para a formação dos alunos, destacaram-se os seguintes comentários:

1. "Acredito que tenha sido uma ótima forma de aprendizado ter feito esta prática. Com certeza para o futuro, caso for preciso utilizar a compostagem, já saberemos como proceder e o que evitar".

2. "A proposta mostrou-se extremamente didática e proveitosa".

3. "Apesar do tempo da presente atividade ser relativamente longo, demandando tempo durante o semestre todo, por vezes sendo cansativa com relação à frequência das aferições da temperatura, a prática foi, sem sombra de dúvidas, a melhor atividade do curso, uma vez que pudemos compreender tecnicamente um novo método para dispor os resíduos orgânicos, uma vez que os aterros se encontram cada vez mais saturados".

4. "O trabalho de compostagem foi realmente muito proveitoso e legal de se realizar. Proveitoso no sentido de saber detalhadamente e na prática o funcionamento da compostagem, que pode ser uma grande opção no gerenciamento de resíduos. E legal, pois foi uma atividade diferente, em que nós realmente podemos nos sentir aplicando aquilo que aprendemos na sala de aula, tendo responsabilidades quase que diariamente para monitoramento do processo, assim como experimentar de uma forma mais realista o espírito do trabalho em equipe e de divisão de tarefas".

5. "Minha sugestão é a flexibilização, fazendo menor e em casa. Eu sei que isso poderia gerar um certo descontrole, mas imagina que bacana seria se toda a família participasse. Isso poderia acabar se tornando uma rotina em casa". 
A partir da avaliação realizada pelos alunos, percebeu-se que o desenvolvimento do projeto temático em questão foi uma proposta pedagógica importante para a formação dos futuros engenheiros uma vez que ela proporcionou a eles um maior envolvimento com o processo de ensino e aprendizagem e um posicionamento crítico, criativo, reflexivo e construtivo frente à comunidade na resolução de problemas.

Além disso, a partir de interações, cooperações, trocas e comprometimentos entre alunos e educadores, ela garantiu a formação de profissionais capacitados para resolver problemas reais e buscar respostas às suas inquietações, pois permitiu conhecer e intervir no real, uma vez que estas duas instâncias não se encontram dissociadas.

Por fim, observou-se que o valor atribuído à experiência não se limitou apenas à aprendizagem em âmbito acadêmico, mas também despertou o interesse em disseminar a técnica da compostagem com a família e a comunidade, uma vez que perceberam que é de simples realização, baixo custo, possibilita a transformação de um resíduo orgânico em um composto para uso no solo e que o processo, se bem conduzido, não atrai vetores, não gera chorume e não é mal cheiroso, podendo ser perfeitamente realizado desde um ambiente doméstico até em escalas industriais ou municipais.

\section{Considerações finais}

O desenvolvimento de projetos temáticos ressignifica o ambiente educativo, transformando-o em um espaço interativo e aberto às múltiplas dimensões do real, em especial, na forma de lidar com os conteúdos das diversas áreas e na configuração daquilo que se entende por ensino e aprendizagem. Nesta proposta, o conhecimento foi construído dentro de um contexto que proporcionou ao aluno o acesso às informações, à investigação, ao aprender a aprender, desafiando-o a buscar uma formação humana, crítica e competente, baseada em uma visão holística para a resolução de seus futuros trabalhos.

O projeto de trabalho realizado na disciplina Gerenciamento e Tratamento de Resíduos Sólidos teve boa aceitação por parte dos alunos, sendo uma proposta alternativa viável para o Ensino de Engenharia, pois considerou a formação global do aluno e tornou o processo de ensino e aprendizagem mais significativo, cooperativo e interessante. Conforme defende Leite (1996), foi possibilitado aos alunos aprender

participando, vivenciando sentimentos, tomando atitudes diante dos fatos, escolhendo procedimentos para atingir determinados objetivos. Ensina-se não só pelas respostas dadas, mas principalmente pelas experiências proporcionadas, pelos problemas criados, pela ação desencadeada. 


\section{Referências}

BEHRENS, M. O paradigma emergente e a prática pedagógica. Curitiba: Champagnat, 2000.

BEHRENS, M.A.; JOSÉ, E.M.A. Aprendizagem por projetos e os contratos didáticos. Diálogo educacional, n. 3, v. 2, p. 79-98, 2001.

BERBEL. N.A.N.; CARVALHO, M. de; DE SORDE, M. R. L.; GIANNASI, M. J.; GUARIENTE, M. H. D. M.; OLIVEIRA, C. C.; SOUZA, M. I. P. de O.; RODRIGUES, S. C.. Avaliação da aprendizagem no ensino superior: Um projeto integrado de investigação através da metodologia da problematização. In: Reunião Anual da ANPEd, n. 23, 2000. Caxambu-MG. Anais..., Caxambu: ANPED, p. 6, 2000.

BRASIL. Lei ${ }^{\circ}$ 12305, de 2 de agosto de 2010. Institui a Política Nacional de Resíduos Sólidos, altera a Lei n 9.605, de 12 de fevereiro de 1998 e dá outras providências. Diário Oficial da União República Federativa do Brasil, Brasília, DF, 3 ago. 2010b. Disponível em: <http://www.planalto.gov.br/ccivil_03/_ato2007-2010/2010/lei/112305.htm>. Acesso em: 22 fev. 2014.

HERNÁNDEZ, F. Transgressão e mudança na educação: os projetos de trabalho. Trad. Jussara Haubert Rodrigues. Porto Alegre, ArtMed, 1998.

HERNÁNDEZ, F; VENTURA, Montserrat. A organização do currículo por projetos de trabalho. Trad. Jussara Haubert Rodrigues. Porto Alegre, ArtMed, 1998.

LEITE, L. H. A. Pedagogia de projetos: intervenção no presente. Presença Pedagógica. Belo Horizonte, n.8, v.2, p.25-33, 1996. Disponível em: < https:// edufisescolar.files.wordpress.com/2011/03/pedagogia-de-projetos-de-lc3bacia-alvarez.pdf>. Acesso em: $06 \mathrm{dez} .2016$.

MAHÉ, V. A pedagogia ativa. 2016. Disponível em: < http://www.pedagogiativa. org/pedagogia-ativa->. Acesso em: 05 dez. 2016.

SANTOS, G.M. A metodologia de aprendizagem por projetos e a prática pedagógica no ensino superior, 10p. 2002. Disponível em: < http://www.portalanpedsul.com.br/admin/uploads/2004/Poster/Poster/02_31_10_A_METODOLOGIA_DE_APRENDIZAGEM_POR_PROJETOS_E_A_PRATICA_PEDAG. pdf > Acesso em: 20 out. 2016. 